\title{
A HISTÓRIA DA MATEMÁTICA NO ENSINO E NA APRENDIZAGEM DO SISTEMA DE NUMERAÇÃO DECIMAL
}

\section{THE HISTORY OF MATHEMATICS IN TEACHING AND LEARNING THE DECIMAL NUMBERING SYSTEM}

\author{
Adriana Borges de Paiva ${ }^{1}$ \\ Universidade Federal de Uberlândia
}

\begin{abstract}
Resumo
Este texto relata alguns dos resultados decorrentes de uma pesquisa de natureza bibliográfica que teve como objetivo principal estudar os sistemas de numeração antigos e suas relações com o sistema de numeração decimal, visando estruturar e planejar ações educativas que fazendo uso da História da Matemática possibilite a adequada compreensão dos conteúdos matemáticos por parte dos estudantes dos anos iniciais do Ensino Fundamental. Inicialmente, o texto discute e analisa o papel da História no processo de ensino e de aprendizagem da Matemática. Posteriormente, apresenta as principais características do sistema de numeração decimal e descreve as principais características dos sistemas de numeração egípcio, babilônico, maia, chinês e romano. Analisa ainda, a importância do ensino e da aprendizagem do sistema de numeração decimal a partir da sua evolução histórica. Pela pesquisa realizada ficou evidenciada que a História da Matemática é uma das estratégias pedagógicas que na atualidade podem efetivamente contribuir para a implementação de uma prática pedagógica que desperta 0 interesse, motiva, estimula a participação ativa dos estudantes e possibilita a aquisição de aprendizagens realmente significativas. Também ficou claro que que o aluno ao estudar o sistema de numeração decimal, sistema atualmente utilizado na maioria dos países, relacionando-o com o estudo de outros sistemas de numeração de outras épocas, terá condições de entendê-lo adequadamente, além de entender que as características que o sistema de numeração decimal apresenta têm origem em outros sistemas de numeração e constatar que a Matemática é um conhecimento dinâmico, fruto da construção permanente de saberes pelos seres humanos.
\end{abstract}

Palavras-chave: História da Matemática; Sistemas de Numeração; Ensino e Aprendizagem.

\begin{abstract}
\section{1 adrianapaiva@ufu.br}

The present work presents results of a research of bibliographic nature that studies the importance of the use of the History of Mathematics as a methodological resource in the development of pedagogical practice in the first years of Elementary School. Without text are the issues related to the teaching of multiplication algorithms. What is new in actions, the techniques and methods they produce and use in the past, in a world, in various regions, for a publication of multiplication recipe, namely: a multiplication done with the hands, a multiplicity developed by the an increase in lattice or multiplication in degree, multiplication made by the Russians and multiplication by the bars created by 
the Scotsman John Napier. The text also presents important ideas that justify the use of the History of Mathematics in the educational process and those that promote the dissemination of knowledge by the learner. The study was carried out using the History of Mathematics as a strategy for the improvement of teaching and for the exercise of curricula in the initial years. The History of Master's Mathematics and Stimulating Killing Participation in the Educational Process, Ending Classroom Development, Closing Session and Questioning, Demonstrating the Evolution of Mathematics and Mathematical Ideas Over Time, in permanent transformation, thus breaking with ideas of some teachers and students who are Mathematics as a static, hermetic knowledge, composed of unquestionable and immutable knowledge.

Keywords: History of Mathematics; Teaching and learning; Multiplication.

\section{Introdução: A história da Matemática no ensino e na aprendizagem}

Os saberes inerentes a História da Matemática são essenciais para a percepção e entendimento do processo de construção do conhecimento matemático envolvendo suas teorias e suas práticas, desenvolvidas e utilizadas em contextos específicos de cada época.

Mendes (2001) a esse respeito esclarece:

[...] o conhecimento partilhado por nós hoje, provém de diferentes grupos sócio-culturais que se organizaram e se desenvolveram intelectualmente de acordo com suas necessidades, interesses e condições de sobrevivência, levados pela mobilidade característica da sociedade humana. Importante também é percebermos como a informação histórica pode contribuir para a disseminação desse conhecimento (MENDES, 2001, p. 18).

Em relação à História da Matemática enquanto uma das propostas para melhor desenvolver a prática pedagógica em Matemática, Della Nina et al., (2005) afirma:

[...] através dessa ferramenta, o professor tem a possibilidade de desenvolver atitudes e valores positivos frente ao conhecimento matemático. $\mathrm{O}$ aluno reconhecerá a Matemática como uma criação humana, que surgiu a partir da busca de soluções para resolver problemas do cotidiano. Conhecerá as preocupações dos vários povos em diferentes momentos históricos identificando a utilização da Matemática em cada um deles e estabelecerá comparações entre os conceitos e processos matemáticos do passado e do presente (DELLA NINA et al., 2005, p. 73).

O conhecimento da Matemática produzido no passado pode, sem dúvida, colaborar na aprendizagem e no desenvolvimento dos conteúdos matemáticos do presente. No entanto, é importante salientar, que teorias e práticas que eram utilizadas para resolver problemas em épocas passadas muito pouco podem contribuir para 
solucionar os problemas de hoje, visto que o contexto atual e a realidade são muito diferentes.

O mais importante, entretanto, é que:

\begin{abstract}
A História da Matemática, mediante um processo de transposição didática e juntamente com outros recursos didáticos e metodológicos, pode oferecer uma importante contribuição ao processo de ensino e aprendizagem em Matemática. Ao revelar a Matemática como uma criação humana, ao mostrar necessidades e preocupações de diferentes culturas, em diferentes momentos históricos, ao estabelecer comparações entre os conceitos e processos matemáticos do passado e do presente, o professor tem a possibilidade de desenvolver atitudes e valores mais favoráveis do aluno diante do conhecimento matemático. Além disso, conceitos abordados em conexão com sua história constituem-se veículos de informação cultural, sociológica e antropológica de grande valor formativo (BRASIL, 1997, p. 45-46).
\end{abstract}

Como visto, a Matemática desenvolvida no passado pode ser importante para o aluno aprender os saberes da Matemática no presente, uma vez que o conhecimento matemático é cumulativo e a produção histórica desse conhecimento é essencial na compreensão de vários conteúdos a serem ensinados nas escolas, principalmente nos primeiros anos do Ensino Fundamental.

A esse respeito, comenta Mendes (2001):

\begin{abstract}
A Matemática como qualquer área do conhecimento humano, tem seu desenrolar evolutivo capaz de caracterizá-la como uma ciência que também se desenvolve a partir da sua própria história. Desse modo podemos buscar nessa história fatos, descobertas e revoluções que nos mostrem o caráter criativo do homem quando se dispõe a elaborar e disseminar a ciência matemática no seu meio sócio-cultural. Cabe-nos, entretanto, o cuidado de saber buscar na história da matemática a medida certa para nos tornarmos capazes de adquirir o espírito presente nesse conhecimento (MENDES, 2001, p. 18).
\end{abstract}

Vale salientar, que ao se desenvolver a prática pedagógica considerando a História da Matemática e dela fazendo uso, é essencial buscar a implementação de uma proposta de ensino dinâmico e diversificado, que considere os interesses de aprendizagem dos alunos e as suas necessidades de formação, mas que sobretudo, relacione os conteúdos escolares que envolvam saberes matemáticos históricos à ciência de hoje.

O conhecimento matemático formalizado, na verdade,

[...] precisa, necessariamente, ser transformado para se tornar passível de ser ensinado/aprendido; ou seja, a obra e o pensamento do matemático teórico 
não são passíveis de comunicação direta aos alunos. Essa consideração implica rever a idéia, que persiste na escola, de ver nos objetos de ensino cópias fiéis dos objetos da ciência (BRASIL, 1997, p. 39).

Outro aspecto importante a ser dito é que a Matemática se relaciona intrinsecamente com as mais diferentes áreas do conhecimento e faz parte da vida cotidiana do aluno, quer, por exemplo, na aquisição e desenvolvimento de habilidades e capacidades de comunicação, na interpretação de informações, na compreensão de questões lógicas, no pensar para solucionar conflitos, no conhecimento e domínio das novas tecnologias.

A História da Matemática, para Gutierre (2011, p. 19), deve fazer parte do ensino da Matemática e o professor "[...] que lança mão desse recurso pode prestar grande auxílio nas aulas, resgatando, além dos aspectos inerentes a algumas demonstrações, o estímulo à imaginação e à criatividade do aluno".

Assim sendo, a utilização da História da Matemática no desenvolvimento das aulas se faz importante, no sentido de que os alunos poderão constatar que a Matemática é um conhecimento produzido pelo ser humano, que ela não é e nunca foi uma ciência isolada das demais e que a Matemática contribui efetivamente para a aquisição de diferentes saberes muito úteis para a vida social.

Ao revelar a Matemática como uma criação humana, ao mostrar necessidades e preocupações de diferentes culturas, em diferentes momentos históricos, ao estabelecer comparações entre os conceitos e processos matemáticos do passado e do presente, o professor tem possibilidade de desenvolver atitudes e valores mais favoráveis do aluno diante do conhecimento matemático (BRASIL,1997, p. 45).

A História da Matemática permite, também, o ensino dos conteúdos matemáticos de forma dinâmica e favorece também a melhoria dos resultados esperados no desenvolvimento das atitudes, habilidades e capacidades que o mundo competitivo moderno exige.

Em muitas situações, o recurso à História da Matemática pode esclarecer idéias Matemáticas que estão sendo construídas pelo aluno, especialmente para dar respostas a alguns "porquês" e, desse modo, contribuir para a constituição de um olhar mais crítico sobre os objetos de conhecimento (BRASIL, 1997, p. 46).

A importância do trabalho com a História da Matemática reside também no fato de motivar o aluno para a aprendizagem de novos conhecimentos. Essa motivação da 
aprendizagem se configura em um significativo desafio para os professores que ensinam Matemática, que para colocá-la em prática deve estar sempre em constante aperfeiçoamento e atualização, obtendo novas informações, obtendo novas técnicas e novas experiências educativas, de tal forma que os seus saberes sobre a História da Matemática lhes permita desenvolver uma prática pedagógica de qualidade junto aos alunos.

É essencial, portanto, entender que nos cursos superiores, nos cursos de extensão e outros,

[...] o conhecimento da história dos conceitos matemáticos precisa fazer parte da formação dos professores para que tenham elementos que lhes permitam mostrar aos alunos a Matemática como ciência que não trata de verdades eternas, infalíveis e imutáveis, mas como ciência dinâmica, sempre aberta à incorporação de novos conhecimentos. Além disso, conhecer os obstáculos envolvidos no processo de construção de conceitos é de grande utilidade para que o professor compreenda melhor alguns aspectos da aprendizagem dos alunos (BRASIL, 1997, p. 38).

\section{Sistemas de numeração: principais características}

Segundo Centurión (1994, p. 21), “[...] um conjunto de símbolos e regras para escrever números é denominado sistema de numeração". O sistema de numeração atualmente utilizado na maioria dos países, denominado sistema indo-arábico, é fruto de um processo histórico e foram divulgados pelos árabes em época relativamente recente. De acordo com Centurión (1994, p. 32), o sistema atual é decimal por isso o chamamos de sistema de numeração decimal.

Para Centurión (1994, p. 32), “[...] a palavra decimal tem sua origem na palavra latina “decem", que significa dez". Conforme essa autora no nosso atual sistema a base é dez, o que significa que os agrupamentos são realizados de dez em dez, provavelmente pela prática que o ser humano tinha de usar os dez dedos das mãos para realizar contagens.

A denominação de indo-arábico para o sistema atual, afirma Centurión (1994, p. 32) "[...] deve-se ao fato de seus símbolos e suas regras terem sido inventados pelo antigo povo indiano e aperfeiçoados e divulgados pelos árabes”. 
O sistema de numeração decimal apresenta como características: o uso de 10 (dez) símbolos, a base é 10, uso do zero, organização em classes e ordens, é posicional, é multiplicativo e é aditivo.

O sistema de numeração indo-arábico é resultado de um processo de evolução histórica. Ao longo da história verifica-se que o ser humano sempre teve a necessidade do registro para representar as quantidades com as quais lidava em seu cotidiano.

Para Centurión (1994, p. 21), as civilizações antigas utilizavam “[...] formas bastante organizadas de escrever os números". Segundo essa autora "[...] é importante conhecê-las, pois o estudo dos antigos sistemas de numeração facilita a compreensão do nosso sistema atual, com seus cálculos e propriedades". A seguir serão descritas as formas como alguns povos (egípcios, babilônicos, maias, chineses e romanos) em épocas diferentes realizavam seus registros numéricos.

Conforme Willerding (1971), os antigos egípcios viviam no vale do Rio Nilo por volta do ano 3000 A.C. e criaram um sistema de numeração que pode ser considerado de base decimal, uma vez que as trocas eram realizadas a cada conjunto de dez símbolos iguais.

Para Boyer (1974), o sistema egípcio e tão antigo como as pirâmides, datando aproximadamente de 5000 anos.

Os egípcios utilizavam sete símbolos distintos em seu sistema de numeração, como pode ser observado no quadro a seguir:

Quadro 1 - Símbolos Egípcios

\begin{tabular}{|c|c|c|c|}
\hline $\begin{array}{c}\text { Símbolo } \\
\text { Egípcio } \\
\end{array}$ & $\begin{array}{c}\text { Símbolo indo- } \\
\text { arábico }\end{array}$ & $\begin{array}{l}\text { Símbolo } \\
\text { Egípcio } \\
\end{array}$ & $\begin{array}{c}\text { Símbolo indo- } \\
\text { arábico }\end{array}$ \\
\hline (haste vertical) & 1 & & 90 \\
\hline & 2 & (corda enr & 100 \\
\hline & 4 & (flor de ló & 1000 \\
\hline
\end{tabular}




\begin{tabular}{|c|c|c|c|}
\hline 111 & 9 & $\underset{(\text { dedo indicador) }}{0}$ & 10000 \\
\hline$\bigcap_{\text {(calcanhar) }}$ & 10 & $\underset{\text { (peixe) }}{\infty}$ & 100000 \\
\hline & 30 & $\begin{array}{l}\text { (homem erguendo os } \\
\text { braços para o céu) }\end{array}$ & 1000000 \\
\hline
\end{tabular}

Fonte: Autoria própria com fundamento em Willerding (1971)

No sistema egípcio cada símbolo podia ser repetido até nove vezes. O sistema era aditivo, ou seja, para determinar o número era necessário somar os valores dos

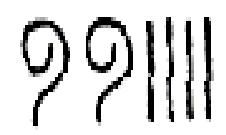

símbolos. Por exemplo:

$$
100+100+1+1+1+1=204
$$

No sistema egípcio não importava a posição do símbolo na escrita, mas sim o valor de cada símbolo, por isso ele não era posicional. Tanto fazia escrever da esquerda para a direita ou da direita para esquerda o resultado era o mesmo observe no exemplo abaixo:

$$
\text { ด) }
$$

Os babilônicos, de acordo com Willerding (1971), viveram no vale entre os Rios Tigres e Eufrates, por volta aproximadamente do ano 2000 A.C., onde hoje é o Iraque. Os símbolos utilizados pelos babilônicos em seu sistema de numeração tinham a forma de cunha e por isso receberam o nome de caracteres cuneiformes. Veja no quadro a seguir os símbolos que eram utilizados:

\begin{tabular}{|c|c|c|c|}
\hline $\begin{array}{r}\text { Símbolo } \\
\text { Babilônico }\end{array}$ & $\begin{array}{c}\text { Símbolo indo- } \\
\text { arábico }\end{array}$ & Símbolo Babilônico & $\begin{array}{c}\text { Símbolo } \\
\text { indo- arábico }\end{array}$ \\
\hline$V$ & 1 & $x<1<1<$ & 50 \\
\hline
\end{tabular}

Quadro 2 - Símbolos Babilônicos 


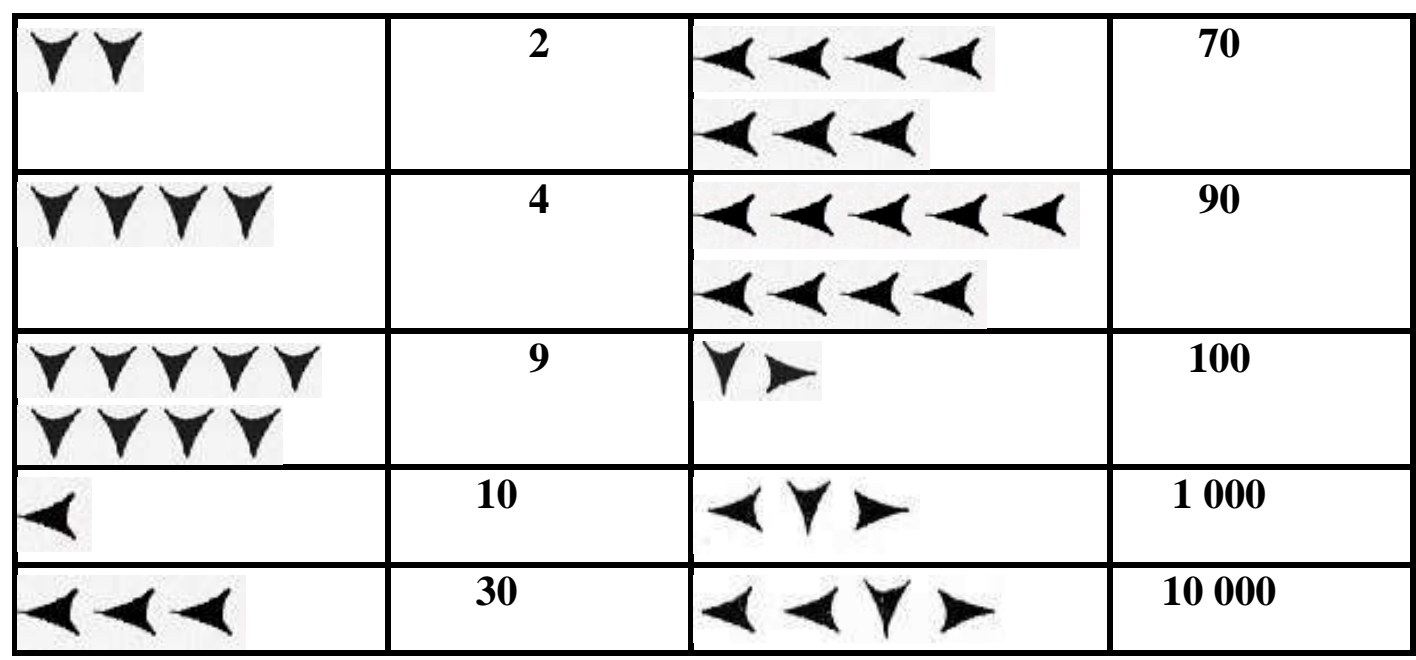

Fonte: Autoria própria com fundamento em Willerding (1971)

Observa-se no quadro acima que no sistema babilônico era utilizado apenas um símbolo $\bigvee$. Esse símbolo representava o 1 que podia ser repetido noves vezes. $\mathrm{O}$ símbolo que representava o 10 era o mesmo só que em outra posição

Estes símbolos quando repetidos tinham seus valores somados. Por exemplo:
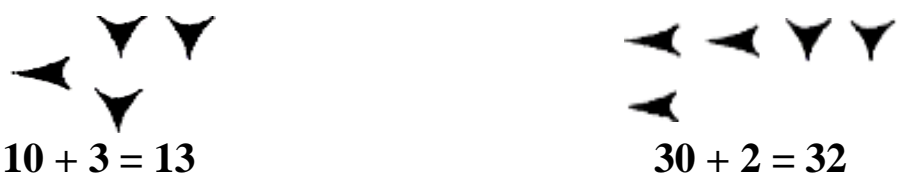

O sistema babilônico era sexagesimal (base 60). Não havia um símbolo para indicar o zero. Eles deixavam um espaço entre os agrupamentos para indicar a posição vazia. Além disso, era posicional (o mesmo símbolo representa valores diferentes conforme a posição que ocupa no numeral). Veja o exemplo abaixo:
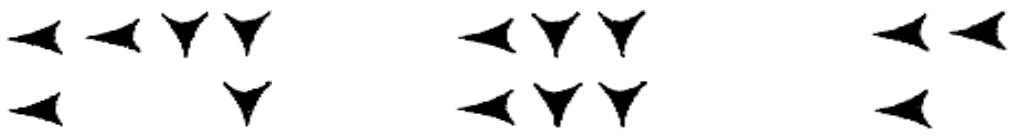

$$
33 \times 60^{2}+24 \times 60^{1}+30 \times 60^{\circ}=118800+1440+30=120270
$$

Como esse número babilônico possui três ordens. $\mathrm{O}$ valor de cada ordem deve ser multiplicado pela potência equivalente da ordem, já que nesse sistema a base é 60 e ele é posicional. Por isso, na $1^{\text {a }}$ ordem temos o 40 que deve ser multiplicado por $60^{\circ}$, na $2^{\mathrm{a}}$ ordem temos o 24 que deve ser multiplicado por $60^{1}$ e na $3^{\mathrm{a}}$ ordem temos o 33 que deve ser multiplicado por $60^{2}$. Se no número tivéssemos uma $4^{\mathrm{a}}$ ordem o valor dessa ordem teria que ser multiplicado por $60^{3}$ e assim sucessivamente. Obtidos os valores de 
cada ordem pela multiplicação eles devem ser somados, portanto o sistema babilônico é também aditivo e multiplicativo.

O sistema chinês é, conforme Willerding (1971), o sistema de numeração mais antigo do mundo e que é usado até hoje. Os chineses usam símbolos para os números de 1 a 10, para cem, para mil e para dez mil, tal como se pode verificar no quadro abaixo:

Quadro 3 - Símbolos Chineses

\begin{tabular}{|c|c|c|}
\hline $1-$ & $6 \div 3$ & 100 百 \\
\hline $2=$ & $7 t$ & 10007 \\
\hline $3 \equiv$ & $8, \smile$ & 10000 萿 \\
\hline $4 \sqrt{2}$ & 9 t & \\
\hline 5 平 & 107 & \\
\hline
\end{tabular}

Fonte: Autoria própria com fundamento em Willerding (1971)

No sistema chinês a escrita é vertical, de cima para baixo. Quando um símbolo de valor menor é escrito antes de um de valor maior, multiplica-se o valor desses símbolos. Veja o exemplo:

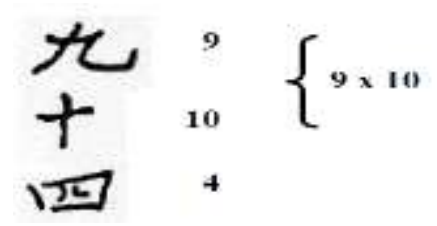

Logo, esse número é:

$$
9 \times 10+4=90+4=\mathbf{9 4}
$$

Pode-se concluir, portanto, que o sistema chinês e multiplicativo e aditivo. Vejamos outro exemplo:

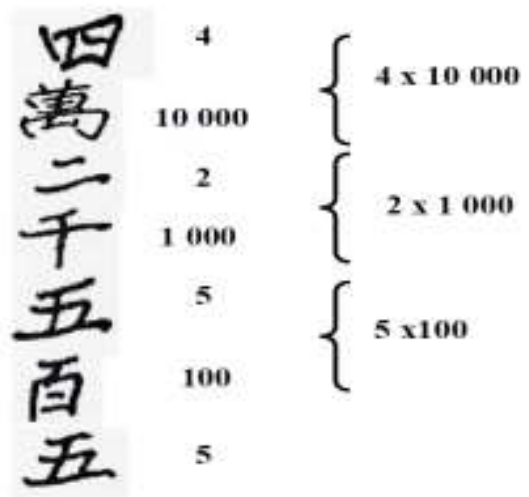

Logo, esse número é: 


$$
4 \times 10000+2 \times 1000+5 \times 100+5=40000+2000+500+5=\mathbf{4 2} \mathbf{5 0 5}
$$

A civilização maia que viveu na América Central, segundo Willerding (1971), utilizava um sistema vigsimal (base vinte). Os símbolos do sistema maia eram representados de 1 a 19 por barras e pontos, sendo que cada ponto representava uma unidade e cada barra representava cinco unidades. Os maias utilizavam o zero que era representado por um olho cerrado. O 20 era por um olho fechado com um ponto acima. No quadro a seguir são apresentados os símbolos utilizados no sistema maia:

Quadro 4 - Símbolos Maias

\begin{tabular}{|c|c|c|c|c|c|c|c|}
\hline 0 & $(0)$ & 5 & $\longrightarrow$ & 10 & $=$ & 15 & $\equiv$ \\
\hline 1 & - & 6 & $\dot{\sim}$ & 11 & $\dot{\square}$ & 16 & $\doteq$ \\
\hline 2 & $\because$ & 7 & . & 12 & 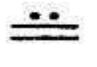 & 17 & 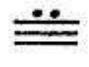 \\
\hline 3 & $\cdots$ & 8 & 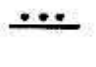 & 13 & 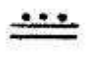 & 18 & 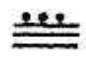 \\
\hline 4 & $\cdots$ & 9 & $\ldots$ & 14 & 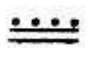 & 19 & $\stackrel{\cdots}{\rightleftharpoons}$ \\
\hline & & & & & & 20 & வ் \\
\hline
\end{tabular}

Fonte: Autoria própria com fundamento em Willerding (1971)

O sistema maia era posicional e os seus valores de posição, segundo Willerding (1971) eram os seguintes:

20 unidades mais baixas (kines - dia) formam 1 uinal

18 uinales formam 1 tun (360 dias, aproximadamente 1 ano)

20 tunes constituem 1 katun (7200 dias)

20 katunes formam 1 ciclo (144 000 dias)

20 ciclos formam 1 grande ciclo (2 880000 dias)

Veja a aplicação nos exemplos abaixo: Exemplo 1:

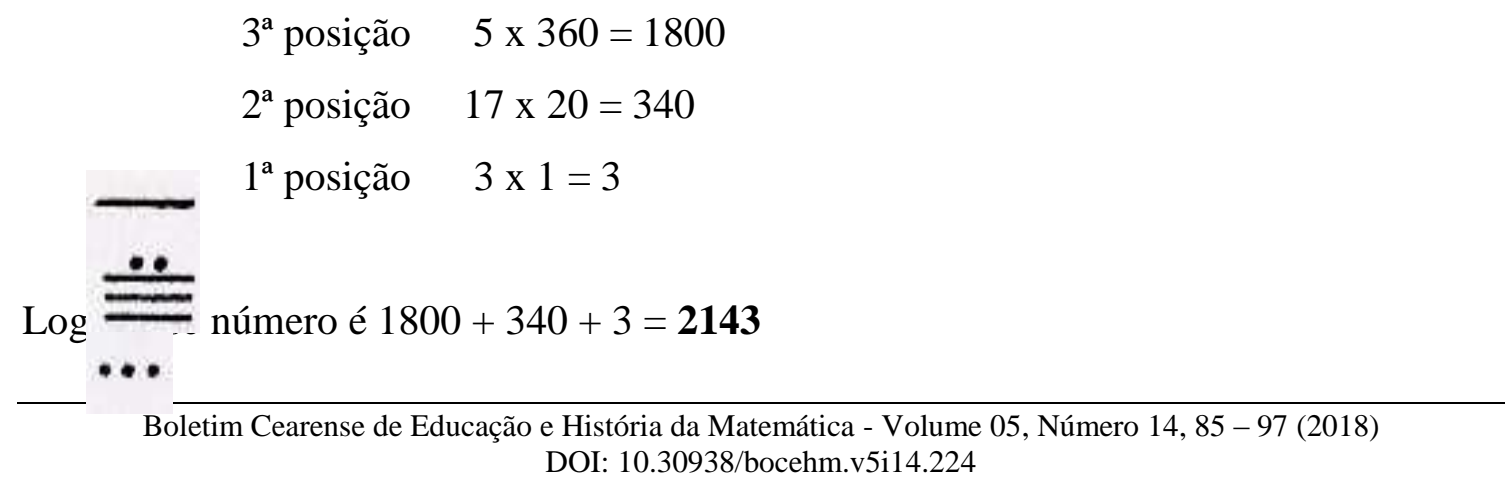


Exemplo 2:

\begin{tabular}{|c|c|c|}
\hline 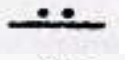 & $5^{\mathrm{a}}$ posição & $7 \times 144000=1008000$ \\
\hline & $4^{\mathrm{a}}$ posição & $0 \times 7200=0$ \\
\hline & $3^{\mathrm{a}}$ posição & $12 \times 360=4320$ \\
\hline & $2^{\mathrm{a}}$ posição & $4 \times 20=80$ \\
\hline & $1^{\mathrm{a}}$ posição & $10 \times 1=10$ \\
\hline
\end{tabular}

Logo, esse número é $1008000+0+4320+10=\mathbf{1 0 1 2} 330$

A partir desses exemplos, constata-se que a leitura e a escrita dos números no sistema maia ocorre de baixo para cima. Verifica-se também que esse sistema é multiplicativo e aditivo.

No sistema romano, de acordo com Willerding (1971), há sete símbolos básicos:

Quadro 5 - Símbolos Romanos

\begin{tabular}{|c|c|c|c|c|c|c|}
\hline I & V & X & L & C & D & M \\
\hline 1 & 5 & 10 & 50 & 100 & 500 & 1000 \\
\hline
\end{tabular}

Fonte: Autoria própria com fundamento em Willerding (1971)

No sistema de numeração romano é usado o princípio da adição para a escrita dos números da seguinte forma:

$$
\text { X X X I I }=30+2 \quad \text { M M D C C V I }=2000+500+200+6
$$

No entanto, quando um valor menor antecede um maior deve-se adotar o princípio subtrativo da seguinte forma:

$$
\text { I V }=4 \quad \text { I X }=9 \quad \text { X L }=40 \quad \text { C D }=400 \quad X \text { C }=90 \quad C ~ M=900
$$

No sistema de numeração romano escreve-se os números da esquerda para a direita em ordem decrescente de valores aplicando-se os princípios aditivos e subtrativos quando necessário. Por exemplo, para escrever o número 2357 aplica-se 
apenas o princípio aditivo: M M C C C L V I I. No entanto para escrever o número 2469 aplica-se os princípios aditivo e subtrativo:

M M C D L X I X ou seja $(1000+1000)+(500-100)+(50+10)+(10-1)$

Para escrever números maiores os romanos adotavam o seguinte procedimento: Para aumentar o valor mil vezes colocavam uma barra em cima do símbolo.

$$
\text { Exemplos: } \overline{X X} \text { V I }=20006 \quad \overline{X X X}=30000
$$

Também havia o entendimento que nos casos de um número menor anteceder um número maior deveria se aplicar a multiplicação.

$$
\text { Exemplos: } \mathrm{XVM}=15 \times 1000=\mathbf{1 5 0 0 0} \quad \mathrm{C} X \mathrm{XM}=120 \times 1000=\mathbf{1 2 0} 000
$$

\section{Considerações finais}

Vários são os fatores que causam desinteresse, baixo rendimento na aprendizagem da Matemática e alto índice de evasões e repetências, dentre eles o fato do processo de ensino não possibilitar a adequada compreensão dos conteúdos matemáticos por parte dos alunos.

A História da Matemática é uma das estratégias pedagógicas que na atualidade podem efetivamente contribuir para a implementação de uma prática pedagógica que desperta o interesse, estimula a participação ativa dos estudantes e possibilita a aquisição de aprendizagens realmente significativas.

Por meio da História da Matemática é possível o aluno estabelecer relações e conexões, entender melhor o conteúdo trabalhado e perceber a importância desta área de conhecimento para a sociedade de maneira geral.

Ao longo do texto, ficou evidenciado que o aluno ao estudar o sistema de numeração decimal, sistema atualmente utilizado na maioria dos países, relacionando-o com o estudo de outros sistemas de numeração de outras épocas, terá condições de entendê-lo adequadamente. Entenderá que as características que o sistema de numeração decimal apresenta têm origem em outros sistemas e constatará que a Matemática é um conhecimento dinâmico, fruto da construção permanente de saberes pelos seres humanos. 


\section{Referências}

BRASIL. Secretaria de Educação Fundamental. Parâmetros Curriculares Nacionais: Matemática. Brasília, DF: MEC/SEF, 1997.

BOYER, C. B. História da Matemática. São Paulo,SP: Ed. Edgard Blücher, 1974.

CENTURIÓN, M. Números e Operações. São Paulo, SP: Scipione, 1994.

DELLA NINA, C. T. et. al; PORTANOVA, R. (Org.) Um currículo de matemática em movimento. Porto Alegre, RS: EDIPUCRS, 2005.

GUTIERRE, L. S. História da Matemática: atividades para a sala de aula. Natal, RN: EDUFRN, 2011.

MENDES, I. A. O uso da História no Ensino da Matemática: reflexões teóricas e experiências. Belém, PA: EDUEPA, 2001.

WILLERDING, M. F. Conceptos Matemáticos: um enfoque histórico. México (D.F.): Editoria Continental, 1971. 